\title{
Effect on antibody and T-cell responses of mixing five GMP-produced DNA plasmids and administration with plasmid expressing GM-CSF
}

\author{
M Sedegah ${ }^{1}$, Y Charoenvit ${ }^{1}$, J Aguiar ${ }^{1}$, J Sacci ${ }^{1,5}$, R Hedstrom ${ }^{1,6}$, S Kumar ${ }^{1,7}$, A Belmonte ${ }^{1}$, DE Lanar ${ }^{2}$, \\ TR Jones ${ }^{1}$, E Abot ${ }^{1}$, P Druilhe ${ }^{3}$, G Corradin ${ }^{4}$, JE Epstein ${ }^{1}$, TL Richie ${ }^{1}$, DJ Carucci ${ }^{1}$ and SL Hoffman ${ }^{1,8}$ \\ ${ }^{1}$ Malaria Program, Naval Medical Research Center, Silver Spring, MD, USA; ${ }^{2}$ Walter Reed Army Institute of Research, Silver Spring, \\ MD, USA; ${ }^{3}$ Parasitologie Biomedicale, Institut Pasteur, France; ${ }^{4}$ Institute of Biochemistry, University of Lausanne, Epalinges, \\ Switzerland
}

\begin{abstract}
One potential benefit of DNA vaccines is the capacity to elicit antibody and T-cell responses against multiple antigens at the same time by mixing plasmids expressing different proteins. A possible negative effect of such mixing is interference among plasmids regarding immunogenicity. In preparation for a clinical trial, we assessed the immunogenicity of GMP-produced plasmids encoding five Plasmodium falciparum proteins, PfCSP, PfSSP2, PfEXP1, PfLSA1, and PfLSA3, given as a mixture, or alone. The mixture induced higher levels of antibodies against whole parasites than did the individual plasmids, but was associated with a decrease in antibodies to individual $P$. falciparum proteins. T-cell responses were in general decreased by administration of the mixture. Immune responses to individual plasmids and mixtures were generally higher in inbred mice than in outbreds. In inbred BALB/C and C57BL/6 mice, coadministration of a plasmid expressing murine granulocyte-macrophage colony-stimulating factor (mGM-CSF), increased antibody and T-cell responses, but in outbred CD-1 mice, coadministration of mGM-CSF was associated with a decrease in antibody responses. Such variability in data from studies in different strains of mice underscores the importance of genetic background on immune response and carefully considering the goals of any preclinical studies of vaccine mixtures planned for human trials.
\end{abstract}

Genes and Immunity (2004) 5, 553-561. doi:10.1038/sj.gene.6364125

Published online 19 August 2004

Keywords: malaria; $T$ lymphocytes; vaccination

\section{Introduction}

One strategy for malaria vaccine development relies upon the induction of antibody and T-cell responses against multiple parasite proteins from different stages of the parasite life cycle. ${ }^{1}$ Because of their ease and simplicity of production, stability, and potential ease of combination, DNA vaccines have seemed to be an ideal method for establishing such immune responses. Our lab has systematically studied DNA malaria vaccines, either as single plasmids or as combinations in mice, ${ }^{2-4}$ rabbits, ${ }^{5}$ non-human primates, ${ }^{6-9}$ and humans. ${ }^{10-12}$ Additionally,

Correspondence: Dr SL Hoffman, Sanaria Inc., 12111 Parklawn Drive, Rockville, MD 20852, USA.

E-mail: slhoffman@sanaria.com

${ }^{5}$ Current address: Department of Microbiology, The University of Maryland School of Medicine, Baltimore, MD, USA

${ }^{6}$ Current address: DynPort Vaccine Company LLC, Frederick, MD, USA

${ }^{7}$ Current address: CBER, Food and Drug Administration, Rockville, MD, USA

${ }^{8}$ Current address: Sanaria Inc., 12111 Parklawn Drive, Rockville, MD 20852, USA

Received 29 April 2004; revised 29 June 2004; accepted 30 June 2004; published online 19 August 2004 we have also studied multiple methods to enhance the immunogenicity and protective efficacy of DNA vaccines in murine and non-human primate systems. One of the best methods to enhance the immunogenicity of DNA vaccines, particularly antibody response in mice, has been co-immunization with a plasmid expressing granulocyte-macrophage colony-stimulating factor (GMCSF). ${ }^{13,14}$ Based upon the results of these previous studies, the decision was made to produce under good manufacturing practice (GMP) conditions five plasmids (four already studied), each of which expressed a different Plasmodium falciparum protein, PfCSP, PfSSP2, PfExp1, PfLSA1, and PfLSA3. The rationale for the choice of the five proteins has been described..$^{15,16}$ In brief, they were all chosen because they are thought to be expressed by radiation-attenuated $P$. falciparum sporozoites in hepatocytes, and individuals immunized with radiation-attenuated $P$. falciparum sporozoites have been shown to have CD8 T-cell responses against all of proteins. ${ }^{17-21}$ To our knowledge, this report provides the first systematic evaluation of multiple $P$. falciparum gene-encoding GMP-grade plasmids as mixtures or on their own, with or without murine GM-CSF, for induction of both antibody and T-cell responses in two different inbred and one outbred strain of mice. 


\section{Results}

Anti-P. falciparum antibody responses

Assessment of anti-P. falciparum parasite antibodies measured by IFAT and ELISA indicated that all five $P$. falciparum DNA plasmids were immunogenic in both outbred CD-1 and inbred BALB/C and C57Bl/6 mice when injected individually. In all strains of mice tested, antibodies to sporozoites or P. falciparum-infected hepatocytes (native proteins) as measured by IFAT were unaltered or increased in the mice injected with the fivegene mixture as compared to the mice that received individual plasmids. (Tables 1a and 1b). However, these IFAT responses in the mice immunized with the mixture are likely to be the sum of responses to individual expressed proteins, since in most cases, mice immunized with single plasmids as compared to those immunized with the mixture, had higher levels of antibodies against the immunizing protein as measured by ELISA (Table 2). In outbred CD-1 mice, as compared with inbred strains, coadministration of mGM-CSF with the plasmid mixture or individual plasmids in most instances led to a decrease in antibody responses measured by IFAT and ELISA (Tables $1 \mathrm{a}, 1 \mathrm{~b}, 1 \mathrm{c}$, and 2). In BALB/c mice

Table 1a Antibodies produced in different strains of mice against $P$. falciparum sporozoites

\begin{tabular}{|c|c|c|c|c|c|c|c|}
\hline \multirow[t]{2}{*}{ Immunization regimen } & \multicolumn{3}{|c|}{$C D-1$} & \multicolumn{2}{|c|}{$B A L B / c$} & \multicolumn{2}{|c|}{ C57BL/6 } \\
\hline & Five-gene mixture & CSP & SSP2 & Five-gene mixture & CSP & Five-gene mixture & SSP2 \\
\hline Individual & & 4064 & 123 & & 8611 & & 640 \\
\hline Individual+mGM-CSF & & 1280 & 220 & & 40960 & & 2560 \\
\hline Effect of mGM-CSF & & $P=0.292$ & $P=0.825$ & & Inc. $P=0.003$ & & Inc. $P=0.003$ \\
\hline Five-gene mixture & 3225 & & & 12177 & & 1810 & \\
\hline Five-gene mixture+mGM-CSF & 538 & & & 24355 & & 14482 & \\
\hline Effect of mGM-CSF & Dec. $P=0.051$ & & & $P=0.19$ & & $P=0.097$ & \\
\hline
\end{tabular}

Geometric mean end-point titers for each group of antibodies against $P$. falciparum sporozoites by IFAT. Assays were carried out with individual sera (eight mice per group for CD-1 mice and four mice per group for BALB/c and C57BL/ 6 mice) collected 2 weeks after the third immunization. Inc. and Dec. indicate whether the titer was significantly increased or decreased by coadministration of mGM-CSF.

Table 1b Antibodies produced in different strains of mice against $P$. falciparum-infected hepatocytes

\begin{tabular}{|c|c|c|c|c|c|c|c|c|c|}
\hline \multirow[t]{2}{*}{ Immunization regimen } & \multicolumn{4}{|c|}{$C D-1$} & \multicolumn{4}{|c|}{$\mathrm{BALB} / \mathrm{c}$} & \multirow{2}{*}{$\begin{array}{c}\text { C57BL/6 } \\
\text { Five-gene } \\
\text { mixture }\end{array}$} \\
\hline & $\begin{array}{c}\text { Five-gene } \\
\text { mixture }\end{array}$ & LSA1 & $L S A 3$ & EXP1 & $\begin{array}{c}\text { Five-gene } \\
\text { mixture }\end{array}$ & LSA1 & $L S A 3$ & EXP1 & \\
\hline Individual & & 100 & Neg & 500 & & 500 & 100 & 250 & \\
\hline Individual +mGM-CSF & & 100 & Neg & 100 & & 1000 & 100 & 250 & \\
\hline Five-gene mixture & 500 & & & & 250 & & & & 250 \\
\hline Five-gene mixture+mGM-CSF & $\mathrm{Neg}$ & & & & 250 & & & & 250 \\
\hline
\end{tabular}

End-point antibody titers of pooled sera from each group (eight mice per group for CD-1 mice and four mice per group for BALB/c and C57BL/6 mice) against $P$. falciparum-infected chimpanzee liver sections by IFAT. Sera were collected 2 weeks after the third immunization. Neg: negative.

Table 1c Antibodies produced in different strains of mice against $P$. falciparum-infected erythrocytes

\begin{tabular}{|c|c|c|c|c|c|c|}
\hline \multirow[t]{2}{*}{ Immunization regimen } & \multicolumn{3}{|c|}{$C D-1$} & \multicolumn{3}{|c|}{$\mathrm{BALB} / \mathrm{c}$} \\
\hline & $\begin{array}{l}\text { Five-gene } \\
\text { mixture }\end{array}$ & PfLSA3 & PfEXP1 & $\begin{array}{l}\text { Five-gene } \\
\text { mixture }\end{array}$ & PfLSA3 & PfEXP1 \\
\hline Individual & & 226 & 1613 & & 1522 & 113 \\
\hline Individual+mGM-CSF & & Neg & 2560 & & 761 & 905 \\
\hline Effect of mGM-CSF & & Dec. $P<0.0009$ & $P=0.456$ & & $P=0.19$ & $P=0.083$ \\
\hline Five-gene mixture & 1280 & & & 40 & & \\
\hline Five-gene mixture+mGM-CSF & 453 & & & 160 & & \\
\hline Effect of mGM-CSF & $P=0.231$ & & & Inc. $P=0.05$ & & \\
\hline
\end{tabular}

Geometric mean end-point titers for each group of antibodies against $P$. falciparum infected erythrocytes by IFAT. Assays were carried out with individual sera (eight mice per group for CD-1 mice and four mice per group for BALB/c and C57BL/ 6 mice) collected 2 weeks after the third immunization. Inc. and Dec. indicate whether the titer was significantly increased or decreased by coadministration of mGM-CSF.

Neg: negative. 
Table 2 Effect of mixing plasmids and adding mGM-CSF in different strains of mice on antibodies against P. falciparum proteins in ELISA

\begin{tabular}{|c|c|c|c|c|c|c|c|c|c|c|}
\hline \multirow[t]{2}{*}{ Immunization regimen } & \multicolumn{5}{|c|}{$C D-1$} & \multicolumn{4}{|c|}{$B A L B / c$} & \multirow{2}{*}{$\begin{array}{c}\text { C57Bl/6 } \\
\text { SSP2 }\end{array}$} \\
\hline & CSP & LSA1 & $L S A 3$ & EXP1 & $S S P 2$ & CSP & LSA1 & $L S A 3$ & EXP1 & \\
\hline Individual & 9671 & 120 & 274 & 17425 & 140 & 13742 & 1013 & 3302 & 15714 & 16053 \\
\hline Five-gene mixture & 3009 & 29 & 14 & 16439 & 280 & 8830 & 14 & 69 & 1654 & 1639 \\
\hline Effect of mixing & $P=0.178$ & $P=0.276$ & $\begin{array}{c}\text { Dec. } \\
P=0.023\end{array}$ & $P=0.927$ & $P=0.72$ & $P=0.181$ & $\begin{array}{c}\text { Dec. } \\
P=0.015\end{array}$ & $\begin{array}{c}\text { Dec. } \\
P=0.009\end{array}$ & $P=0.126$ & $P=0.14$ \\
\hline Individual+mGM-CSF & 5834 & 27 & 24 & 32792 & 49 & 55436 & 1771 & 1681 & 25293 & 115678 \\
\hline Effect of mGM-CSF & $P=0.52$ & $P=0.24$ & $\begin{array}{c}\text { Dec. } \\
P=0.039\end{array}$ & $P=0.25$ & $P=0.71$ & Inc. $P=0.013$ & $P=0.69$ & $P=0.467$ & $P=0.551$ & $P=0.06$ \\
\hline $\begin{array}{l}\text { Five-gene } \\
\text { mixture+mGM-CSF }\end{array}$ & 424 & 17 & 8 & 6106 & 100 & 21087 & 28 & 122 & 222 & 31563 \\
\hline
\end{tabular}

ELISA against recombinant proteins of $P$. falciparum, PfCSP, PfSSP2, PfLSA1, PfLSA3, and PfEXP1, was carried out with individual sera (eight mice per group for CD-1 mice and four mice per group for BALB/c and C57BL/ 6 mice) collected two weeks after the third immunization. For each individual sera, the results were recorded as OD 0.5 units (the reciprocal of the serum dilution at which the mean OD reading was 0.5). The geometric mean of the OD 0.5 unit for each group is reported. Inc. and Dec. indicate whether the titer was significantly increased or decreased by mixing or by coadministration of mGM-CSF. In all the five-gene mixture groups, the effect of mGM-CSF was not statistically significant.

however, coadministration of mGM-CSF with the mixture of plasmids or individual plasmids resulted in variable antibody responses measured by IFAT and ELISA, although there was a trend toward higher responses, particularly in IFAT against sporozoites (Tables 1a, 1b, 1c, and 2). The antibody responses against sporozoites and recombinant proteins were generally higher in inbred mice (BALB/c and C57BL/6 mice), as compared to levels obtained in outbred CD-1 mice (Tables 1a, and 2). The groups in which the increase or decrease in antibody reached significant levels are shown in Tables $1 \mathrm{a}, 1 \mathrm{~b}, 1 \mathrm{c}$, and 2 .

With PfEXP1, in addition to the use of recombinant proteins, we also used synthetic peptides to assess the antibody response induced to $\mathrm{N}$ - and C-terminal PfExp1 peptides. Interestingly, we observed a low antibody response pattern to the synthetic peptide derived from the N-terminal portion of PfEXP-1 (amino acids (aa) 23105 sequence) and high antibody response to the synthetic peptide derived from the C-terminal portion of PfEXP-1 (aa 73-161 sequence) in CD-1 and BALB/c mice immunized with the five-gene mixture or with the PfEXP-1 plasmid alone (Table 3). This pattern of response, obtained with DNA immunization in mice, is similar to that observed in individuals from Mali and Burkina Faso with long-term exposure to malaria. ${ }^{22}$ These authors reported that antibodies to the sequence 73-162 of Pf EXP-1 were found in $70 \%$ of adult donors and strikingly, the N-terminal fragment, aa 23-105, was only weekly recognized by a few donors.

\section{Antigen-specific T-cell responses after plasmid immunization}

We assessed antigen-specific T-cell responses after immunization using cytotoxic $\mathrm{T}$ cell (CTL) and IFN $\gamma$ ELISPOT assays. Responses to $P f$ proteins were measured 2 weeks after the second and third doses of vaccines. The response to each antigen was assessed in mice immunized with the single plasmid or the mixture. Similar patterns of T-cell responses were obtained after
Table 3 Antibody titers against the $\mathrm{N}$ - and C-terminal synthetic peptides in CD-1 and BALB/c mice immunized with PfEXP-1 as part of the five-gene mixture or with the PfEXP-1 plasmid alone

\begin{tabular}{|c|c|c|c|c|}
\hline \multirow{2}{*}{$\begin{array}{l}\text { Immunization } \\
\text { regimen }\end{array}$} & \multicolumn{2}{|c|}{$C D-1$} & \multicolumn{2}{|c|}{$B A L B / c$} \\
\hline & $\begin{array}{l}\text { N-term } \\
\text { EXP1 (aa } \\
\text { 23-105) }\end{array}$ & $\begin{array}{l}\text { C-term } \\
\text { EXP1 (aa } \\
\text { 73-161) }\end{array}$ & $\begin{array}{l}\text { N-term } \\
\text { EXP1 (aa } \\
\text { 23-105) }\end{array}$ & $\begin{array}{c}\text { C-term } \\
\text { EXP1 (aa } \\
\text { 73-161) }\end{array}$ \\
\hline Individual & 31 & 10797 & 23 & 5336 \\
\hline $\begin{array}{l}\text { Five-gene } \\
\text { mixture }\end{array}$ & 27 & 14519 & 18 & 1325 \\
\hline Effect of mixing & & $\begin{array}{c}\text { Inc. } \\
P=0.702\end{array}$ & & $\begin{array}{c}\text { Dec. } \\
P=0.382\end{array}$ \\
\hline
\end{tabular}

ELISA against synthetic peptides of $P$. falciparum, PfEXP1, was carried out with individual sera (eight mice per group for CD-1 mice and four mice per group for BALB/c mice) collected 2 weeks after the third immunization. For each individual sera, the results were recorded as OD 0.5 units (the reciprocal of the serum dilution at which the mean OD reading was 0.5 ). The geometric mean of the OD 0.5 unit for each group is reported. Inc. and Dec. indicate whether the titer was significantly increased or decreased by mixing.

two and three doses of vaccine; only data following the third dose of vaccine are reported. No positive T-cell responses to any of the tested $P$. falciparum antigens were obtained in unimmunized mice (data not shown).

Anti-PfCSP T-cell responses: The studies were carried out in BALB/c mice and included Groups 1, 2, 3, 4, and 13 (Table 4) and results are shown in Table 5. When compared to the group that received the PfCSP plasmid alone, CTL response to PfCSP was reduced in the group that received the five-gene mixture $(P=0.003, t$-test $)$, as was the IFN $\gamma$ response by ELISPOT $(P=0.032, t$-test) (Table 5). Coadministration of PfCSP DNA with mGMCSF resulted in no statistical change in CTL $(P=0.240, t-$ test) but increased ELISPOT ( $P=0.001, t$-test) responses. 
Table 4 Immunization regimens

\begin{tabular}{|c|c|c|c|}
\hline Group no. & Mice & Plasmid DNA vaccine & Dose $(\mu g)$ \\
\hline 1 & \multirow[t]{2}{*}{ CD-1, BALB/c, and C57BL/6 } & Multiplasmid $(5 \times 100 \mu \mathrm{g}$ each $)$ & 500 \\
\hline 2 & & Multiplasmid+mGM-CSF & $500+50$ \\
\hline 3 & \multirow[t]{2}{*}{ CD-1 and BALB/c } & VCL-2510 (CSP) & 100 \\
\hline 4 & & VCL-2510 (CSP)+mGM-CSF & $100+50$ \\
\hline 5 & \multirow[t]{2}{*}{ CD-1 and C57BL/6 } & VCL-2519 (SSP2) & 100 \\
\hline 6 & & VCL-2519 (SSP2)+mGM-CSF & $100+50$ \\
\hline 7 & \multirow[t]{2}{*}{ CD-1 and BALB/c } & VCL-2523 (EXP1) & 100 \\
\hline 8 & & VCL-2523 (EXP1)+mGM-CSF & $100+50$ \\
\hline 9 & \multirow[t]{2}{*}{ CD-1 and BALB/c } & VCL-2551 (LSA1) & 100 \\
\hline 10 & & VCL-2551 (LSA1)+mGM-CSF & $100+50$ \\
\hline 11 & \multirow[t]{2}{*}{ CD-1 and BALB/c } & VCL-2556 (LSA3) & 100 \\
\hline 12 & & VCL-2556 (LSA3)+mGM-CSF & $100+50$ \\
\hline 13 & CD-1, BALB/c, and C57BL/6 & Uninjected & \\
\hline
\end{tabular}

Table 5 Effect of mixing and adding mGM-CSF on CTL and IFN $\gamma$ ELISPOT response against P. falciparum antigens in BALB/c mice (CSP, LSA1, and EXP1) and in C57BL/6 mice (SSP2)

\begin{tabular}{|c|c|c|c|c|c|c|c|c|}
\hline \multirow[t]{2}{*}{ Immunization Regimen } & \multicolumn{4}{|c|}{$C T L$} & \multicolumn{4}{|c|}{ ELISPOT } \\
\hline & CSP & SSP2 & $L S A 1$ & EXP1 & CSP & SSP2 & $L S A 1$ & $E X P 1^{\mathrm{a}}$ \\
\hline Individual & 39 & 45 & 23 & 41 & 50 & 74 & 58 & 8 \\
\hline Five-gene mixture & 8 & 29 & 60 & 1 & 38 & 72 & 98 & 1 \\
\hline Effect of mixing & Dec. $P=0.003$ & $P=0.139$ & Inc. $P=0.006$ & Dec. $P=0.001$ & Dec. $P=0.032$ & $P=0.528$ & $P=0.076$ & \\
\hline $\begin{array}{l}\text { Individual+mGM-CSF } \\
\text { Effect of mGM-CSF }\end{array}$ & $\begin{array}{c}47 \\
P=0.24\end{array}$ & $\begin{array}{c}41 \\
P=0.57\end{array}$ & $\begin{array}{c}60 \\
\text { Inc. } P=0.018\end{array}$ & $\begin{array}{c}76 \\
P=0.12\end{array}$ & $\begin{array}{c}266 \\
\text { Inc. } P=0.001\end{array}$ & $\begin{array}{c}216 \\
\text { Inc. } P=0.015\end{array}$ & $\begin{array}{c}459 \\
\text { Inc. } P=0.001\end{array}$ & 16 \\
\hline
\end{tabular}

CTL assays were carried out as described in Materials and methods. Spleen cells were pooled from four mice per group 2 weeks after the third immunization, restimulated, and used. Data are represented as percent specific lysis, which is defined as percent lysis with antigenspecific targets-percent lysis with control targets. ELISPOT assays were carried out as described in Materials and methods. Freshly isolated spleen cells were pooled from four mice per group 2 weeks after the third immunization, and incubated with P. falciparum antigens or controls. Data are represented as antigen-specific IFN $\gamma$-producing cells per million spleen cells. Inc. and Dec. indicate whether the antigen specific lysis or number of spots per million was significantly increased or decreased by mixing or adding mGM-CSF.

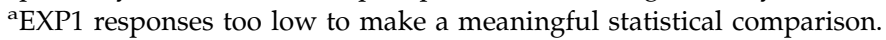

Coadministration of the five-gene mixture with mGMCSF did not alter the reduced response to PfCSP in the mice immunized with the five-gene mixture (data not shown). The CTL responses induced by immunization with the PfCSP plasmid, administered alone or coadministered with mGM-CSF, were genetically restricted and dependent on CD8 + T cells (Figure 1).

PfSSP2 T-cell response: The studies were carried out in C57BL/ 6 mice and included Groups 1, 2, 5, 6, and 13, as detailed in Table 4. CTL and ELISPOT results are shown in Table 5. In the ELISPOT assay, compared to the group that received the SSP2 alone, IFN $\gamma$ ELISPOT responses to SSP2 were not significantly altered in the group that received the mixture of five plasmids $(P=0.528, t$-test $)$ (Table 5). Coadministration of mGM-CSF resulted in increased ELISPOT response to PfSSP2 $(P=0.015, t$-test; Table 5). The CTL responses induced by immunization with the PfSSP2 plasmid, administered alone or coadmi- nistered with mGM-CSF, were genetically restricted and dependent on CD8 + T cells (Figure 1).

PfLSA1 response: The studies were carried out in BALB/c mice and included Groups 1, 2, 9, 10, and 13, as detailed in Table 4 with results shown in Table 5. Compared to the group that received the PfLSA1 plasmid alone, CTL and ELISPOT responses to LSA1 were increased ( $P=0.006$ and 0.076 respectively, $t$-test) in the group that received the mixture of five plasmids (Table 5). Coadministration of mGM-CSF resulted in an increase in CTL $(P=0.018, t$-test $)$ and ELISPOT $(P=0.001, t$-test) responses (Table 5$)$. The CTL responses induced by immunization with the PfLSA1 plasmid, administered alone or with mGM-CSF, were genetically restricted and dependent on CD8 $+\mathrm{T}$ cells (Figure 1).

PfEXP1 response: The studies undertaken in BALB/c mice and included Groups 1, 2, 7, 8, and 13, as detailed in Table 4 with results shown in Table 5 . Compared to the 


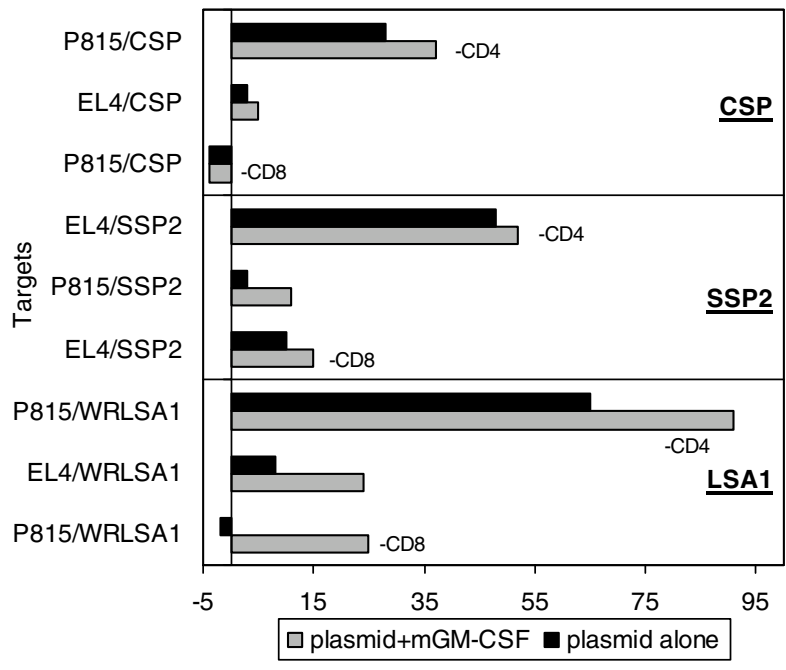

Figure 1 Genetic restriction and CD8 + T-cell dependence of CTL response. CTL response. CTL assays were carried out as described in Materials and methods. Spleen cells were pooled from four mice per group 2 weeks after the third immunization, restimulated and used. Data are represented as percent specific lysis, which is defined as percent lysis with positive targets-percent lysis with negative targets. PfCSP CTL response. At an effector to target ratio of 40:1, T cells from BALB/c mice immunized with PfCSP or PfCSP plus mGM-CSF lysed MHC matched P815 cells $\left(\mathrm{H}-2^{\mathrm{d}}\right)$ pulsed with PfCSP (39-47) peptide, but low level lysis was obtained with peptidepulsed EL-4 cells $\left(\mathrm{H}-2^{\mathrm{b}}\right)$. Cytolytic activity was eliminated by depletion of $\mathrm{CD} 8{ }^{+} \mathrm{T}$ cells but remained high after the depletion of CD4 ${ }^{+}$T cells. PfSSP2 response. At an effector to target ratio of 40:1, T cells from C57BL/6 mice immunized with PfSSP2 or PfSSP2 plus mGM-CSF lysed MHC matched EL4 cells $\left(\mathrm{H}-2^{\mathrm{b}}\right)$ pulsed with PfSSP2 (214-233) peptide, but very low level lysis was obtained with peptide-pulsed mismatched $\mathrm{P} 815$ cells $\left(\mathrm{H}-2^{\mathrm{d}}\right)$. Cytolytic activity was significantly reduced by depletion of $\mathrm{CD}^{+}{ }^{+} \mathrm{T}$ cells, but remained high after the depletion of $\mathrm{CD}^{+}{ }^{+} \mathrm{T}$ cells. PfLSA1 response. At an effector to target ratio of 40:1, T cells from BALB/c mice immunized with PfLSA1 lysed MHC matched P815 cells $\left(\mathrm{H}-2^{\mathrm{d}}\right)$ infected with recombinant virus WRPfLSA1 to a higher level than with WRPfLSA1-infected EL-4 (H-2 $\left.{ }^{\mathrm{b}}\right)$ mismatched target cells. Cytolytic activity was eliminated or reduced drastically by depletion of CD8 ${ }^{+}$ $\mathrm{T}$ cells, but remained high after depletion of $\mathrm{CD} 4{ }^{+} \mathrm{T}$ cells.

group that received the PfEXP1 plasmid alone, CTL responses to PfEXP1 were significantly lower $(P=0.001$, $t$-test) in the group that received the mixture of five plasmids (Table 5). In mice that received PfEXP1 alone, coadministration of $\mathrm{mGM}-\mathrm{CSF}$ resulted in increased CTL $(P=0.12, t$-test $)$ and IFN $\gamma$ responses $(P=0.021, t$-test $)$ (Table 5). The IFN $\gamma$ response to EXP1 was very low in all groups compared to responses to the other antigens. Of note, IFN $\gamma$ responses by ELISPOT to EXP1 using a peptide including a CD8 + T-cell epitope, unlike CTL responses to this peptide, are generally low. This may indicate that the T-cell precursors that respond to this epitope are low, hence the low response obtained in the ELISPOT assay, which utilizes cells without the 7-day in vitro re-stimulation performed with the CTL assay. No depletion experiments were undertaken.

\section{Discussion}

In general, it is much easier to induce immune responses in mice with DNA vaccines than it is in non-human primates and humans. Yet, here we show that many of the mice showed poor responses, and that immunizing with the mixture often led to significant reduction of antibody and T-cell responses. We also show that the immune-enhancing responses of the GMP-grade plasmid expressing mGM-CSF were antigen and strain specific.

Our studies demonstrated that all plasmid components of the mixture, when injected as individual plasmids, were immunogenic. The antibodies to individual proteins and the T-cell responses to peptides were in general, but not in all cases, reduced when a plasmid was administered as a mixture, as compared to when it was administered alone. However, mixing increased the antibody response to the parasite as measured by IFAT, perhaps due to induction of responses against multiple proteins simultaneously (Table 1a). We have also shown in another study this reduction in immune responses to individual proteins when given as a nine-gene mixture to mice. ${ }^{23}$ In that study, we demonstrated that the reduction was due to interference among plasmids in a mixture as opposed to a dose effect of the plasmids. ${ }^{23}$ Thus, we believe that the reduction in immune responses to individual proteins in the mixture, as opposed to when they were delivered alone in the current studies, was due to interference. Another possibility is that of a dose effect. In this study, the total amount of plasmid DNA injected in the groups that received gene mixtures was $500 \mu \mathrm{g}$ per mouse, while those administered individual plasmids received $100 \mu \mathrm{g}$ of the specific P. falciparum plasmid with or without $50 \mu \mathrm{g}$ of the GM-CSF plasmid. It is unlikely that the reduced responses to some antigens in the mixture were due to a simple suppressive effect of the higher dose of total DNA in those groups. In a previous experiment, we measured the antibody responses induced after injecting increasing amounts of a single plasmid and found no suppressive effect in the higher dose groups. In those experiments, three groups of mice received 50, 200, or $400 \mu \mathrm{g}$ of plasmid encoding Plasmodium yoelii circumsporozoite protein (PyCSP), and the geometric mean IFA titers obtained after immunization were 3805,3620 , and 4413 , respectively. In another study, we measured the interferon- $\gamma$ responses to CSP when different doses of PfCSP were delivered alone or in a mixture containing four other plasmids encoding PfSSP2, PfLSA1, PfAMA1 (apical merozoite antigen 1), and PfMSP1 (merozoite surface protein 1, $42 \mathrm{kDa}$ carboxy-terminal fragment, 3D7). We gave four doses at 4-week intervals and the assay was performed 2 weeks after the last immunization. At these lower plasmid doses, spot-forming cells per million spleen cells for the 2,10 , and $50 \mu \mathrm{g}$ groups in the multigene group were 70 , 109 , and 62, while spot forming cells per million spleen cells for the CSP-alone groups were 195, 704, and 708 respectively (M Sedegah, unpublished).

The results also showed that, in general, the immune responses were increased by coadministration of murine GM-CSF to inbred BALB/c and C57BL/ 6 mice, and decreased when coadministered to outbred CD-1 mice. Our previous murine studies showed that coadministration of murine GM-CSF with P. yoelii CSP plasmid enhanced antibody responses and protective immunity in BALB/c mice. ${ }^{13,14}$ Since no antibodies were produced in the first single-gene human trials with PfCSP DNA vaccine, ${ }^{10,11}$ human GM-CSF was coadministered with the five-gene mixture vaccine in some of the groups in 
the MuSTDO 5 human trial; the analysis of this study is in preparation (TL Richie, unpublished). However, our results here demonstrated that the effects of coadministration of a plasmid expressing mGM-CSF with Pf plasmids are not consistent. We found that the effect on the immune response of coadministering plasmid encoding mGM-CSF depended on the mouse strain. In CD1 mice, coadministration of mGM-CSF generally led to a reduction in antibody response (by both IFA and ELISA). In inbred BALB/c and C57BL/ 6 mice however, coadministration of mGM-CSF generally led to an increase in both antibody and IFN $\gamma$ ELISPOT responses (Tables 1a, $1 b, 1 c, 2$, and 3). With all antigens, the trend was that responses were generally increased, although not always reaching statistical significance. It is interesting however to note that coadministration of a plasmid encoding PfMSP1 (not included in this study) with a plasmid encoding rhesus GM-CSF did not lead to enhanced antibody or T-cell responses in rhesus monkeys. ${ }^{24}$ More importantly, when humans were immunized with a mixture of the same five plasmids included in this study, addition of a plasmid encoding human GM-CSF to the mixture did not lead to increased T-cell responses (RW Wang and SL Hoffman, unpublished)

We have shown that administration of the five-gene mixture vaccine altered the immune response to some of the proteins encoded by the individual components of the five-gene mixture as compared to that of the plasmid administered alone. We are unable to determine if the result was due to specific antigenic interactions. We are also unable to determine the significance of the reduced ELISA antibody response in terms of protective immunity. Despite these ELISA results, administration of the mixture of plasmids generally led to higher levels of antibodies to the native parasite as measured in IFAT against the different parasitic developmental stages including sporozoites and liver stage parasites. Planning of clinical human trials is ongoing and results may show the predictive value of these murine data. Taken together, these data indicate that it will be much more difficult than anticipated to use mixtures of DNA plasmids as human vaccines, and that more systematic study than previously anticipated will be necessary to adequately evaluate and optimize such plasmid mixtures.

\section{Materials and methods}

\section{Plasmids}

The construction of four of the six plasmids used in this study, VCL-2510 (CSP), VCL-2519 (SSP2), VCL-2523 (EXP1), and mGM-CSF plasmid DNA construct (VR1701), has been previously described.4,10,11,13 VCL-2556 (LSA3) was constructed by cloning the full-length LSA-3 gene into the BamHI site of the mammalian expression plasmid VR1020. The LSA3 gene was amplified from the blood stage cDNA of the 3D7 strain of P. falciparum. VCL2551 (LSA1) encoded for approximately $65 \%$ of LSA1 and was constructed as a recombinant fusion between the amino-terminal and carboxyl-terminal regions (without the central repeat region). The PCR-amplified $1315 \mathrm{bp}$ LSA1 gene fragment was cloned into the BamHI site in VR1020. All the P. falciparum plasmids used in this study were GMP produced at Vical Inc., CA, USA.

\section{Mice}

Female 4- to 6-week-old outbred CD-1 mice were purchased from Charles River Laboratories (Wilmington, MA, USA). Female 4- to 6-week-old inbred BALB/cByJ and C57BL/6 mice were purchased from The Jackson Laboratory (Bar Harbor, ME, USA).

\section{Route of injections and dose interval}

In an effort to induce high levels of both antibodies and CTL activity in the same animal, we administered the plasmids by both intramuscular (i.m. ) and intradermal (i.d.) routes. We have previously shown that in some strains of mice, administration of DNA plasmids i.m. produces the highest levels of $\mathrm{CD} 8+\mathrm{T}$-cell responses and Th1 CD4 T-cell responses, and administration by the i.d. route induces higher antibody responses (M Sedegah, unpublished). Furthermore, we have reported that in rabbits, administration of DNA by both i.m. and i.d. routes in the same animal gave higher levels of antibodies than did administration by the i.d. route alone. ${ }^{5}$ In humans, because of the limitations of administering more than $100 \mu \mathrm{l}$ by i.d. at a single site by needle, it will be difficult to administer large quantities of DNA by this route alone. Thus, we chose to administer the DNA by both i.m. and i.d. for these studies. Two-thirds of the total dose was administered i.m. and the remaining one-third was administered i.d. as detailed below. The i.m. dose was administered in a volume of $100 \mu \mathrm{l}$ of phosphate-buffered saline ( $\mathrm{pH} 7.4)$. A $0.3 \mathrm{ml}$ insulin syringe with a $29 \mathrm{G}$ gauge $1 / 2$ inch was used for the i.m. injections in the tibialis anterior muscle of the two hind limbs such that $50 \mu \mathrm{l}$ was administered in each hind limb. The i.d. dose was administered in a volume of $50 \mu \mathrm{l}$ PBS, split equally in each of three sites at the base of the tail. Three immunizations were administered at 4week intervals.

\section{Immunization groups}

Table 4 depicts details of the experimental groups. Groups 1-13 were studied in outbred CD-1 mice for antibody response to all the five $P$. falciparum antigens under study. All experimental groups described above, with the exception of Groups 5 and 6, were also repeated in BALB/c mice to study T-cell responses against PfCSP, PfLSA1, and PfEXP1. Groups 1, 2, 5, 6, and 13 were also repeated in $\mathrm{C} 57 \mathrm{BL} / 6$ mice to study $\mathrm{T}$-cell responses against PfSSP2. Inbred mice were selected based on the availability of previously identified peptides and reagents required for T-cell assays. In order to be consistent, each of the individual plasmids encoding the $P$. falciparum antigens was always given in a dose of $100 \mu \mathrm{g}$ while the GM-CSF-encoding plasmid was given as $50 \mu \mathrm{g}$. In previous studies, we found that there is a dose response in antibody titer against sporozoites when one increases the dose from 0.5 to $50 \mu \mathrm{g}$ of the PfCSP plasmid (geometric mean titers against $P$. falciparum sporozoites in IFAT: $0.5 \mu \mathrm{g}-10,5 \mu \mathrm{g}-48,50 \mu \mathrm{g}-2560$ ). Furthermore, when immunizing with a $P$. yoelii CSP plasmid, there was little difference in antibody response as the dose increased from 50 to $400 \mu \mathrm{g}$ (geometric mean titers against $P$. yoelii sporozoites in IFAT: $50 \mu \mathrm{g}-3805$, $200 \mu \mathrm{g}-3620,400 \mu \mathrm{g}-4413)$ (M Sedegah, unpublished). 
Antigens for ELISA

ELISA IgG responses to the proteins encoded by the five $P$. falciparum genes were measured.

PfCSP: Recombinant $P$. falciparum CSP (3D7) encoding for aa $\mathrm{L}_{19}-\mathrm{N}_{405}$ from the 3D7 clone of the parasite was expressed as an intracellular protein in Escherichia coli. The procedure for expression and purification of this protein has been described earlier. ${ }^{25}$

PfSSP2: Recombinant P. falciparum SSP2 (3D7) was expressed as an intracellular protein in E. coli. The gene fragment encoding for aa $\mathrm{D}_{48}-\mathrm{K}_{394}$ was PCR-amplified from the 3D7 strain of parasite genomic DNA using gene-specific sense and antisense primers. The PCRamplified SSP2 gene was cloned into modified E. coli expression plasmid pET32 (Novagen, Madison, WI, USA). At the $\mathrm{NH}_{2}$-terminus to SSP2 gene are 48 aa that encode for the $\mathrm{HIS}_{6}$ tag, an S-tag site and an enterokinase cleavage site, and at the C-terminal end of SSP2 are an additional 11 aa that encode for $\mathrm{HIS}_{6}$ tag. Recombinant SSP2 plasmid was transformed into an E. coli expression strain and recombinant protein was purified on a $\mathrm{Ni}$ NTA agarose column.

PfLSA1: Recombinant LSA1 encoding for the Cterminal region of LSA1 from the 3D7 strain of $P$. falciparum was expressed as an intracellular protein in $E$. coli. The gene fragment encoding for aa $E_{1628}-L_{1909}$ was PCR-amplified from the parasite genomic DNA using gene-specific sense and antisense primers. The PCRamplified LSA1 gene was digested with NcoI/BamHI restriction enzymes and then cloned into the $E$. coli expression plasmid pET-60 (Qiagen, Valencia, CA, USA). This plasmid is designed to add a $\mathrm{HIS}_{6}$ tag to the Cterminal of the expressed protein. The resultant recombinant LSA1 plasmid was transformed into the E. coli expression strain M15. Recombinant protein was produced by growing the bacteria to log-phase growth in shaker flasks and expression was induced by the addition of $0.5 \mathrm{~mm}$ IPTG for $2 \mathrm{~h}$. E. coli cells were lysed by sonication and recombinant LSA1 was purified by two-step purification on a Ni-NTA agarose column.

PfLSA3: Recombinant PfLSA3 protein (GST-NN), encoding for aa 869-1786 from the K1 strain of $P$. falciparum was expressed in E. coli and prepared as previously described. ${ }^{26}$

PfEXP1: PfEXP1 recombinant protein used in the ELISA was a gift from Hoffmann-La Roche, Basel, Switzerland. The full-length Exp-1 gene, also known as 5.1 antigen, was cloned from the $\mathrm{K} 1$ strain of $P$. falciparum and was produced in vitro from recombinant plasmid pUC8-5.1 and purified as previously described. ${ }^{27}$ Previously described PfEXP1 synthetic peptides ${ }^{22}$ that included the N-terminal (aa 23-105) and C-terminal (aa 73-162) sequences were also used.

The optimal concentrations $(0.5-4.0 \mu \mathrm{g} / \mathrm{ml})$ of recombinant proteins and peptides to be used were first determined by standard ELISA and used in subsequent experiments as solid phase antigens.

\section{Detection of antibodies to $P$. falciparum pre-erythrocytic stage antigens}

Pooled sera obtained at 2 weeks after the second immunization and individual sera obtained after the third immunization were analyzed for reactivity with $P$. falciparum pre-erythrocytic stage antigens using IFAT and ELISA.
IFAT: Using previously described methods, ${ }^{11}$ IFAT was carried out using $P$. falciparum air-dried sporozoites, cryosections of chimpanzee livers infected with $P$. falciparum liver stage parasites, and air-dried parasitized erythrocytes obtained from in vitro parasite cultures.

ELISA: Sera obtained from individual mice 2 weeks after the third immunization were analyzed by ELISA against $P$. falciparum proteins by standard ELISA protocols previously described. ${ }^{28}$ Color reaction was measured in a micro-ELISA-automated reader (Dynatech, MR5000) at OD $410 \mathrm{~nm}$. Mean values of the OD readings of quadruplicate assays were recorded. The results were recorded as OD 0.5 units (the interpolated reciprocal of the serum dilution expected to give an OD reading of 0.5 ) and the GEOMEAN OD unit for each mouse group was reported.

\section{Recombinant viruses for T-cell assays}

Recombinant viruses used in the T-cell studies have all been described.,9 Recombinant vaccinia virus NYVAC expressing LSA1 (vP1197) was used to stimulate effector cells for CTL assays. Recombinant virus WR expressing LSA1 (vP1253) and WR wild type were used for preparing positive and negative target cells. The $P$. falciparum genes were all from the 3D7 clone.

\section{Peptides for T-cell assays}

The three peptides used included $\mathrm{H}-2^{\mathrm{d}}$ peptide $P f C S P$ aa 39-47 NYDNAGTNL, ${ }^{29} \mathrm{H}-{ }^{\mathrm{b}}$ peptide PfSSP2 (3D7) aa 214-233 LYADSAWENVKNVIGPFMKA, ${ }^{30}$ and $\mathrm{H}-2^{\mathrm{d}}$ peptide PfEXP1 (3D7) EVNKRKSKYKLATSV. ${ }^{4}$

\section{CTL assay}

Effectors stimulated with recombinant pox virus-infected antigen-presenting cells: P815 cells (American Type Culture Collection, Rockville, MD, USA) were used to prepare antigen-presenting cells (APCs) to stimulate spleen cells from BALB/c mice immunized with plasmid containing PfLSA1. At 1 day prior to setting up the effector cells for the CTL assay (day -1), P815 cells were infected for $90 \mathrm{~min}$ with NYVACPfLSA1 recombinant virus at 5 multiplicities of infection (MOI). APCs were incubated at $37^{\circ} \mathrm{C}$ and $5 \% \quad \mathrm{CO}_{2}$ overnight at a cell concentration of $1 \times 10^{6} / \mathrm{ml}$ in complete medium consisting of RPMI 1640 medium supplemented with $10 \%$ heat-inactivated fetal calf serum, L-glutamine, and $50 \mathrm{U} /$ $\mathrm{ml}$ each of penicillin and streptomycin. On the day when effector cells were set up (day 0), APCs were washed three times, suspended in $2 \mathrm{ml}$ complete medium, and irradiated at $10000 \mathrm{rad}$. After counting, APCs were resuspended at a cell concentration of $4 \times 10^{5} / \mathrm{ml}$ in complete medium containing 2-mercaptoethanol $\left(5 \times 10^{-5} \mathrm{M}\right)$ and plated at $1 \mathrm{ml}$ per well of a 24-well plate. A total of $6 \times 10^{6}$ spleen cells suspended in $1 \mathrm{ml}$ of complete medium were added to each of the wells already containing $1 \mathrm{ml}$ of APCs and cultures were incubated at $37^{\circ} \mathrm{C}$ and $5 \% \mathrm{CO}_{2}$ for 7 days.

Effectors stimulated with peptide: Starting on day 0 , spleen cells suspended in complete medium at a concentration of $6 \times 10^{6} / 2 \mathrm{ml}$ were stimulated for a total of 7 days with $10 \mu \mathrm{g} / \mathrm{ml}$ of peptide at $37^{\circ} \mathrm{C}$ and $5 \% \mathrm{CO}_{2}$. Previously identified $\mathrm{H}-2^{\mathrm{d}}$ and $\mathrm{H}-2^{\mathrm{b}}$ peptides PfCSP 3947 NYDNAGTNL, PfSSP2 (3D7) 214-233 LYADSAWENVKNVIGPFMKA, and PfEXP1 (3D7) EVNKRKSKYKLATSV were used for the peptide stimulation. On 
day 2 ( 2 days after setting up effector cells with peptide), $200 \mu \mathrm{l}$ of T-Stim culture supplement (Collaborative Biomedical Products) was added to each well and further incubated for 5 more days.

Recombinant poxvirus-infected target cells: On the day before the CTL assay was performed (day 6 after setting up the effector cells), target cells were infected with the recombinant or parental control virus at $5 \mathrm{MOI}$ and incubated overnight in complete medium at $37^{\circ} \mathrm{C}$ and $5 \%$ $\mathrm{CO}_{2}$. On the day of assay, virus-infected target cells were washed once and the cell pellet was labeled with $0.1 \mathrm{mCi}$ of ${ }^{51} \mathrm{Cr}$ for $1 \mathrm{~h}$. After three washes, cells were counted and used in the chromium release assay at 5000 target cells suspended in $100 \mu \mathrm{l}$ per well.

\section{Peptide-labeled target cells}

On day 6 after setting up the effector cells, target cells were pulsed with the CTL peptide under test or irrelevant control peptide at $10 \mu \mathrm{g} / \mathrm{ml}$ in the presence of $0.1 \mathrm{mCi}$. of ${ }^{51} \mathrm{Cr}$ and incubated overnight. The same series of peptides used for the stimulation of effector cells were used. On the day of assay, peptide-labeled target cells were washed three times, cells were counted and used in the chromium release assay at 5000 target cells suspended in $100 \mu \mathrm{l}$ per well.

${ }^{51} \mathrm{Cr}$ release assay: A standard ${ }^{51} \mathrm{Cr}$ release assay was carried out. The effector cells were washed three times, counted and suspended in complete medium at $2 \times 10^{6} /$ $\mathrm{ml}$ and tested with 5000 target cells (both experimental and control targets) in a 96-well U-bottomed plate. A 5hour standard chromium release method was followed and percent lysis was calculated. Assays were carried out in triplicate and percent lysis was defined as (experimental cpm-spontaneous cpm)/(maximum cpm-sponspontaneous $\mathrm{cpm}) \times 100 \%$. Spontaneous release was obtained as cpm of targets in the presence of medium, and maximum cpm was obtained as cpm of targets in the presence of $5 \%$ Triton X-100.

\section{Depletion of T-cell subsets}

Anti-CD8 + - or anti-CD4-coated Dynabeads (Dynal Inc.,. Great Neck, NY, USA) were used to deplete effector cells of CD8 + or CD4 + T cells according to the manufacturer's instructions. Depleted cells were tested against positive targets.

\section{IFN $\gamma$ ELISPOT}

Effectors: The number of $P$. falciparum antigen-specific IFN $\gamma$-producing cells was determined in freshly isolated spleen cells using modified methods previously described. ${ }^{31,32}$ Spleen cells from mice that 14 days earlier had received their second or third immunization were used in these determinations. These measurements were made $36 \mathrm{~h}$ after being incubated at $37^{\circ} \mathrm{C}$ and $5 \% \mathrm{CO}_{2}$ with target cells infected with recombinant poxvirus expressing P. falciparum proteins or incubated with peptides.

ELISPOT assay: 96-well nitrocellulose plates (Millipore Corp., Bedford, MA, USA) were coated with $100 \mu$ of PBS containing $5 \mu \mathrm{g} / \mathrm{ml}$ of purified rat anti-mouse IFN $\gamma$ $\mathrm{mAb}$ (PharMingen, San Diego, CA, USA). After overnight incubation at room temperature, the wells were repeatedly washed with culture medium and incubated for $1 \mathrm{~h}$ with $100 \mu \mathrm{l}$ of culture medium. The starting concentration for the freshly isolated spleen cells was 16$36 \times 10^{6} / \mathrm{ml}$ and two-fold dilutions in triplicate were assayed. One set of effector cells was cocultured with irradiated virus-infected APCs. Target cells were used at $2-4 \times 10^{5}$ cells $/ \mathrm{ml}$ and dispensed at $100 \mu \mathrm{l}$ per well. Peptides suspended in complete medium were added to spleen cells so that APCs in the whole spleen cell population were used to present peptide to effector cells. The same series of peptides used for the CTL assay, PfCSP (3D7) 39-47 NYDNAGTNL, PfSSP2 (3D7) 214-233 LYADSAWENVKNVIGPFMKA, and PfEXP1 (3D7) EVNKRKSKYKLATSV, were used. Peptides were used at a concentration of $10 \mu \mathrm{g} / \mathrm{ml}$ and dispensed at $100 \mu \mathrm{l}$ per well. After incubation at $37^{\circ} \mathrm{C}$ and $5 \% \mathrm{CO}_{2}$ for $36 \mathrm{~h}$, the plates were extensively washed with PBS containing $0.05 \%$ Tween 20 (PBS/T). The wells were then incubated with $100 \mu \mathrm{l}$ of a solution of $1 \mu \mathrm{g} / \mathrm{ml}$ of biotinylated antimouse IFN $\gamma-\mathrm{mAb}$ (Pharmingen, San Diego, CA, USA) in PBS/T. After overnight incubation at $4^{\circ} \mathrm{C}$, wells were washed with PBS/T and $100 \mu$ l of peroxidase-labeled streptavidin (Kirkegaard and Perry Laboratories, Gaithersburg, MD, USA) at a dilution of 1/1000 in PBS/T was added to each well. After 1-h incubation at room temperature, wells were washed twice with PBS/T and PBS each. The spots were developed by following the manufacturer's instructions provided with the DAB Reagent set (Kirkegaard and Perry Laboratories, Gaithersburg, MD, USA). Spots corresponding to IFN $\gamma$ producing cells in wells containing the different spleen cell dilutions were counted with the aid of a stereomicroscope and the results were expressed as the number of IFN $\gamma$-secreting cells per $10^{6}$ spleen cells.

\section{Statistical analysis}

To compare the effect of mixing plasmids or adding mGM-CSF in the different groups studied, $P$-values were generated using Student's $t$-test on $\log _{(10)}$-transformed values using SPSS for Windows (SPSS Inc., Chicago, IL, USA, ver 8.0).

\section{Acknowledgements}

We are grateful to Romeo Wallace, Victoria Fallame Majam, and Harini Ganeshan for technical support. We thank Dr WR Weiss for discussions and editorial assistance. The experiments reported here were carried out according to the principles set forth in the 'Guide for the Care and Use of Laboratory Animals', Institute of Laboratory Animals Resources, National Research Council, National Academy Press, 1996. This study was supported by Naval Medical Research Center work unit \#A2284. The opinions and assertions herein are the private ones of the authors and are not to be construed as official or as reflecting the views of the US Navy, the US Department of Defense, or the US Government.

\section{References}

1 Hoffman SL, Franke ED, Hollingdale MR, Druilhe P. Attacking the infected hepatocyte. In: Hoffman SL (ed). Malaria Vaccine Development: A Multi-Immune Response Approach. ASM Press: Washington, DC, 1996, pp 35-75.

2 Sedegah M, Hedstrom R, Hobart P, Hoffman SL. Protection against malaria by immunization with plasmid DNA encod- 
ing circumsporozoite protein. Proc Natl Acad Sci USA 1994; 91 : 9866-9870.

3 Doolan DL, Sedegah M, Hedstrom RC, Hobart P, Charoenvit $\mathrm{Y}$, Hoffman SL. Circumventing genetic restriction of protection against malaria with multi-gene DNA immunization: CD8+ T cell, interferon-gamma, and nitric oxide dependent immunity. J Exp Med 1996; 183: 1739-1746.

4 Hedstrom RC, Doolan DL, Wang R et al. In vitro expression and in vivo immunogenicity of Plasmodium falciparum preerythrocytic stage DNA vaccines. Int J Mol Med 1998; 2: 29-38.

5 Aguiar JC, Hedstrom RC, Rogers WO et al. Enhancement of the immune response in rabbits to a malaria DNA vaccine by immunization with a needle-free jet device. Vaccine 2001; 20: 275-280.

6 Jones TR, Narum DL, Gozalo AS et al. Protection of Aotus monkeys by Plasmodium falciparum EBA-175 primeprotein boost immunization regimen. J Infect Dis 2001; 183: 303-312.

7 Jones TR, Gramzinski RA, Aguiar JC et al. Absence of antigenic competition in Aotus monkeys immunized with Plasmodium falciparum DNA vaccines delivered as a mixture. Vaccine 2002; 20: 1675-1680.

8 Rogers WO, Baird JK, Kumar A et al. Multistage multiantigen heterologous prime boost vaccine for Plasmodium knowlesi malaria provides partial protection in rhesus macaques. Infect Immun 2001; 69: 5565-5572.

9 Wang R, Doolan DL, Charoenvit Y et al. Simultaneous induction of multiple antigen-specific cytotoxic $\mathrm{T}$ lymphocytes in nonhuman primates by immunization with a mixture of four Plasmodium falciparum DNA plasmids. Infect Immun 1998; 66: 4193-4202.

10 Wang R, Doolan DL, Le TP et al. Induction of antigen-specific cytotoxic $\mathrm{T}$ lymphocytes in humans by a malaria DNA vaccine. Science 1998; 282: 476-480.

11 Le TP, Coonan KM, Hedstrom RC et al. Safety, tolerability and humoral immune responses after intramuscular administration of a malaria DNA vaccine to healthy adult volunteers. Vaccine 2000; 18: 1893-1901.

12 Wang R, Epstein J, Baraceros FM et al. Induction of CD4(+) T cell-dependent $\mathrm{CD} 8(+)$ type 1 responses in humans by a malaria DNA vaccine. Proc Natl Acad Sci USA 2001; 98: 10817-10822.

13 Weiss WR, Ishii KJ, Hedstrom RC et al. A plasmid encoding murine granulocyte-macrophage colony-stimulating factor increases protection conferred by a malaria DNA vaccine. J Immunol 1998; 161: 2325-2332.

14 Sedegah M, Weiss W, Sacci Jr JB et al. Improving protective immunity induced by DNA-based immunization: priming with antigen and GM-CSF encoding plasmid DNA and boosting with antigen expressing recombinant poxvirus. J Immunol 2000; 164: 5905-5912.

15 Kumar S, Epstein JE, Richie TL et al. A multilateral effort to develop DNA vaccines against falciparum malaria. Trends Parasitol 2002; 18: 129-135.

16 Hoffman SL, Doolan DL. Malaria vaccines-targeting infected hepatocytes. Nat Med 2000; 6: 1218-1219.

17 Malik A, Egan JE, Houghten RA, Sadoff JC, Hoffman SL. Human cytotoxic $\mathrm{T}$ lymphocytes against the Plasmodium falciparum circumsporozoite protein. Proc Natl Acad Sci USA 1991; 88: 3300-3304.
18 Sedegah M, Sim BKL, Mason C et al. Naturally acquired CD8+ cytotoxic $\mathrm{T}$ lymphocytes against the Plasmodium falciparum circumsporozoite protein. J Immunol 1992; 149: 966-971.

19 Weiss WR, Berzovsky JA, Houghten RA, Sedegah M, Hollingdale $M$, Hoffman SL. A $\mathrm{T}$ cell clone directed at the circumsporozoite protein which protects mice against both Plasmodium yoelii and Plasmodium berghei. J Immunol 1992; 149: 2103-2109.

20 Doolan DL, Hoffman SL. The complexity of protective immunity against liver-stage malaria. J Immunol 2000; 165: 1453-1462.

21 Perlaza BL, Sauzet JP, Balde AT et al. Long synthetic peptides encompassing the Plasmodium falciparum LSA3 are the target of human B and T cells and are potent inducers of B helper, $\mathrm{T}$ helper and cytolytic T cell responses in mice. Eur J Immunol 2001; 31: 2200-2209.

22 Meraldi V, Nebie I, Moret R et al. Recognition of synthetic polypeptides corresponding to the $\mathrm{N}$ - and $\mathrm{C}$-terminal fragments of Plasmodium falciparum Exp-1 by T-cells and plasma from human donors from African endemic areas. Parasite Immunol 2002; 24: 141-150.

23 Sedegah M, Charoenvit Y, Minh L et al. Reduced immunogenicity of DNA vaccine plasmids in mixtures. Gene Therapy 2004; 11: 448-456.

24 Kumar S, Villinger F, Oakley $\mathrm{M}$ et al. A DNA vaccine encoding the $42 \mathrm{kDa} C$-terminus of merozoite surface protein 1 of Plasmodium falciparum induces antibody, interferon-gamma and cytotoxic $\mathrm{T}$ cell responses in rhesus monkeys: immunostimulatory effects of granulocyte macrophage-colony stimulating factor. Immunol Lett 2002; 81: 13-24.

25 Kolodny N, Kitov S, Vassell MA et al. Two-step chromatographic purification of recombinant Plasmodium falciparum circumsporozoite protein from Escherichia coli. J Chromatogr $B$ 2001; 762: 77-86.

26 Daubersies $\mathrm{P}$, Thomas AW, Millet $\mathrm{P}$ et al. Protection against Plasmodium falciparum malaria in chimpanzees by immunization with the conserved pre-erythrocytic liver-stage antigen 3. Nat Med 2000; 6: 1258-1263.

27 Caspers P, Etlinger H, Matile H, Pink JR, Stuber D, Takacs B. A Plasmodium falciparum malaria vaccine candidate which contains epitopes from the circumsporozoite protein and a blood stage antigen, 5.1. Mol Biochem Parasitol 1991; 47: 143-150.

28 Charoenvit Y, Mellouk S, Cole C et al. Monoclonal, but not polyclonal antibodies protect against Plasmodium yoeli sporozoites. J Immunol 1991; 146: 1020-1025.

29 Blum Tirouvanziam U, Servis C, Habluetzel A et al. Localization of HLA-A2.1-restricted T cell epitopes in the circumsporozoite protein of Plasmodium falciparum. J Immunol 1995; 154: 3922-3931.

30 Wizel B, Rogers WO, Houghten RA, Lanar DE, Tine JA, Hoffman SL. Induction of murine cytotoxic T lymphocytes against Plasmodium falciparum sporozoite surface protein 2 . Eur J Immunol 1994; 24: 1487-1495.

31 Miyahira Y, Murata K, Rodriguez D et al. Quantification of antigen specific CD8+ T cells using an ELISPOT assay. J Immunol Methods 1995; 181: 45-54.

32 Sedegah M, Jones TR, Kaur $\mathrm{M}$ et al. Boosting with recombinant vaccinia increases immunogenicity and protective efficacy of malaria DNA vaccine. Proc Natl Acad Sci USA 1998; 95: $7648-7653$. 